\title{
Aerodynamics Analysis on Wings with Winglets and Vortex Generators
}

\author{
ABDUL QADER HASAN \\ Department of Mechanical \\ Engineering \\ Abu Dhabi University \\ Abu Dhabi, P.O. Box 59911 \\ UNITED ARAB \\ EMIRATES
}

\author{
NASR M. AL-KHUDHIRI \\ Department of Mechanical \\ Engineering \\ Abu Dhabi University \\ Abu Dhabi, P.O. Box 59911 \\ UNITED ARAB \\ EMIRATES
}

\author{
MUHAMMAD A. IQBAL \\ Department of Mechanical \\ Engineering \\ Abu Dhabi University \\ Abu Dhabi, P.O. Box 59911 \\ UNITED ARAB \\ EMIRATES
}

\author{
SHARUL SHAM DOL \\ Department of Mechanical \\ Engineering \\ Abu Dhabi University \\ Abu Dhabi, P.O. Box 59911 \\ UNITED ARAB \\ EMIRATES
}

\author{
ABID ABDUL AZEEZ \\ Department of Mechanical \\ Engineering \\ Abu Dhabi University \\ Abu Dhabi, P.O. Box 59911 \\ UNITED ARAB \\ EMIRATES
}

\author{
MOHAMED S. GADALA \\ Department of Mechanical \\ Engineering \\ Abu Dhabi University \\ Abu Dhabi, P.O. Box 59911 \\ UNITED ARAB \\ EMIRATES
}

\begin{abstract}
This project was based on the principle of designing, simulating and developing an inexpensive, aerodynamically efficient and regular class electric powered $\mathrm{RC}$ aircraft. This prototype was designed to have the maximum strength to weight ratio with minimum drag coefficient (and highest lift coefficient). Moreover, all constraints provided by SAE International competition were followed. The investigation was conducted for the complete airplane and for wing optimization. The model was numerically investigated with ANSYS Fluent 16.1 through the SST K-Omega turbulence model at Reynolds number of 360,000. Once the results were obtained, model and result verification were done by wind tunnel test to validate the data. It was concluded that the airplane with $45^{\circ}$ winglet has the highest lift force with minimal drag and $45^{\circ}$ winglet was further modified with rectangular and triangular vortex generators in order to further enhance its aerodynamic efficiency for a range of Angle of Attacks (AOA).
\end{abstract}

Key-Words: - aerodynamics; CFD; drag; lift; vortex generators; wind tunnel; winglet

Received: June 3, 2020. Revised: November 12, 2020. Accepted: November 24, 2020.

Published: December 7, 2020.

\section{Introduction}

This project is specifically based on the design, fabrication and simulative analysis of an aerodynamically efficient radio-controlled (RC) aircraft which will officially contest at SAE International competition USA (previously known as the Society of Automotive Engineers). There are set of rules and regulations posed by SAE every year for potential contestants; all these instructions are kept under consideration during this process. The aim of the competition is primarily to design and prototype a radio-controlled (RC) aircraft that will lift the largest payload while still maintaining structural integrity [1]. This paper will shed focus on the aerodynamic elements of the wings design.

The main parameters in aerodynamics analysis (i.e. lift, drag, airfoil lift to drag ratio, thrust and center of pressure) are influenced by the angle of attack [2-4]. As the angle of attack is increased, the overall lift of the plane increases until a certain angle of attack due to the asymmetrical effects. This specific angle is known as the critical angle of attack. Beyond this angle, flow separation occurs over the top surface of the airfoil eventually causing the 
aircraft to stall. Maximum lift angle depends on the airfoil shape and the aircraft speed. Wind tunnel experiments are carried out to determine this critical angle of attack for this modified aircraft wings.

Moreover, lift and drag are the optimum parameters in defining wing's overall performance in the shape of Lift to Drag ratio (L/D) [5]. The lift force is produced due to the pressure difference above and below the wing. This can be further discussed in terms of the circulations [6]. Since the pressure is higher on the top surface of the wing than the lower surface, there is an exchange of air through the tips of the wings forming vortices at the wing tips. These trailing vortex from the left and right side of the wing are joined by the bound vortex along the length of the wing. This combined vortex system is known as the horseshoe vortex and is responsible for the lift generated for the wing. The strength of the trailing vortex is directly proportional to the strength of lift generated.

These wing tip vortices - due to the pressure distribution leaks around the wing tips - induce a small component of air velocity downstream of the wing known as the downwash [2]. This downwash velocity tends to combine with the free stream velocity and form the local relative wind. This downwash tends to shift the vector of lift forming the horizontal component as the induced drag component. The induced drag is the largest drag produced when aircraft is at low speeds and it tends to decrease with increasing speeds. The application of winglets can reduce the strength of these wing tip vortices hence reducing the induced drag [7]. They are utilized to enhance the performance of the planes by increasing the cruising speed and reducing the fuel consumption, emissions and nose. However, winglets can have various installation angles for aerodynamics enhancement and this is yet to be fully explored.

Vortex generator is another potential modification that can be applied on the top leading edge surface of the wings [8-9]. Vortex generators produce small vortices on the surface of the wings, which combine the high energy free-stream air into the low energy boundary layer. This allows the airflow inside the boundary layer to cope with the adverse pressure gradient resulting in delayed flow separation. Rough surface also encourages turbulent boundary layer resulting in reducing the pressure drag. It keeps the flow to remain attached with the surface leading to reduce the wake region behind the aircraft. The question whether this approach would increase the limit of stalling to higher angles of attack, needs additional investigation for answers.
This research further extended the work by [7] to analyze the effects of modified wings but at various angle of attacks in order to provide answers to the above-mentioned question. Figure 1 shows the profile of the airfoil that was selected for this work. It is the e420-il- EPPLER 420 Airfoil. The primary purpose is to determine the lift and drag forces by incorporating various wing modifications which includes $45^{\circ}$ winglet, $90^{\circ}$ winglet, rectangular and triangular vortex generators. The Computational Fluid Dynamics (CFD) results were also validated by wind tunnel experiments, performed at the aircraft operating turbulent flow condition for Reynolds number of 360,000 .

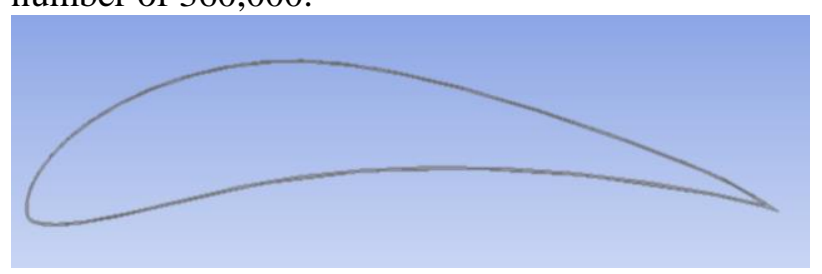

Figure 1 EPPLER 420 airfoil.

\section{Materials and Methods}

\subsection{Geometry and Meshing}

ANSYS Workbench was used to model the exact shape of our wing. Airfoil tools was the prime source of importing airfoil EPPLER 420 graphic points. Furthermore, these graphical points were utilized in workbench to create the geometry of our airfoil followed by full wing. Thereafter, enclosure tool was brought to action enclosing our geometry in rectangular box. Subsequently, the rectangular box was subtracted from the wing using the Boolean. With that being mentioned, enclosure plays a paramount role by carving a boundary for the flow to pass over the geometry. Furthermore, meshing operation was profoundly done with multiple refinements on the wing. Figure 2 shows 631,763 elements and 113,864 nodes applied on the wing and winglet. Figure 3 displays 9 different cases of wing modification at 0-degree angle of attack. Comparatively, the results using winglet modifications showed a slight increase in lift and decrease in drag forces, which makes this structure aerodynamically more efficient than the simple wing. 

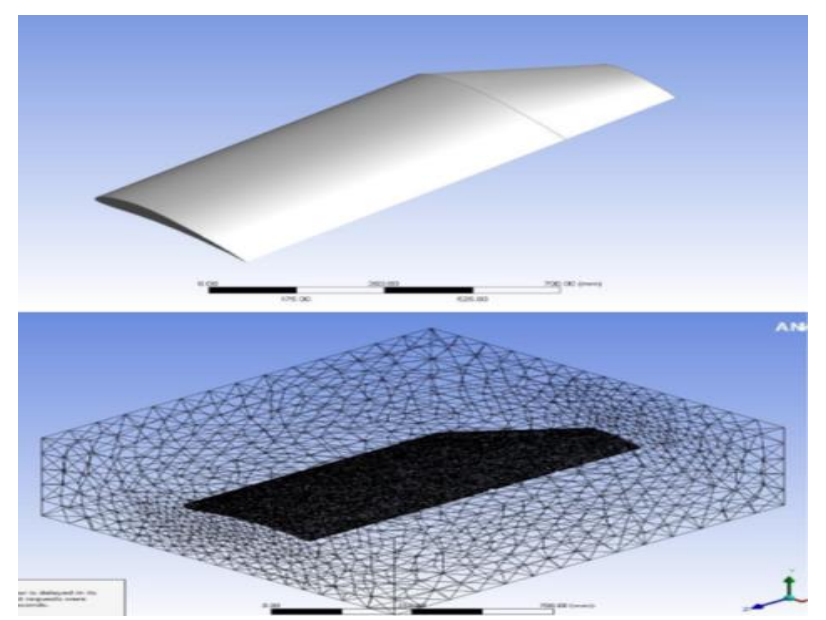

Figure 2 Geometry of the simple wing and its meshing.

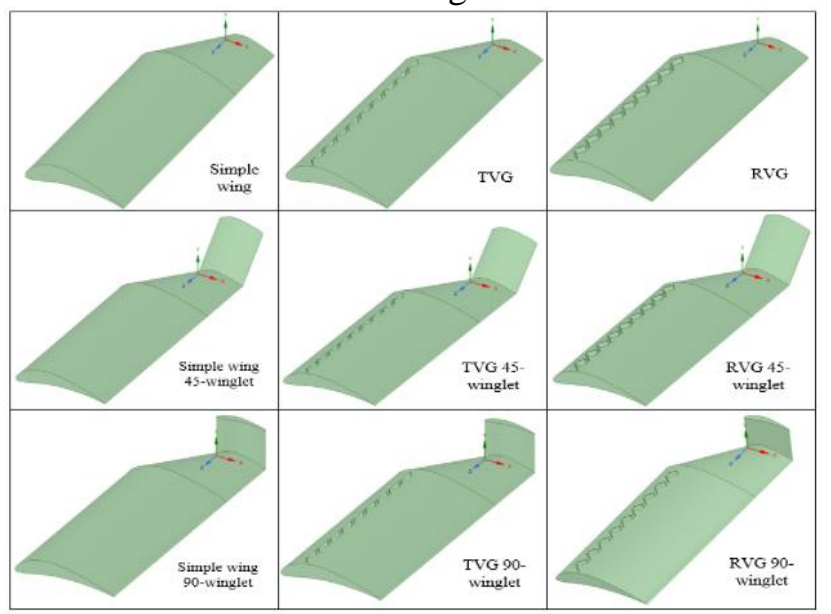

Figure 3 Wing modifications / Cases; VG-Vortex Generator; TVG- Triangle Vortex Generator; RVGRectangle Vortex Generator.

The full geometric body of the aircraft was built using the workbench software. All steps were followed sequentially starting with the fuselage; then wings, vertical and horizontal stabilizers with original dimensions. This aircraft was modified with $45^{\circ}$ winglets, as shown in Fig. 4. These winglets were made with the sweep function available in workbench where a straight $45^{\circ}$ line was created with $25 \mathrm{~cm}$ dimension; the airfoil and the pathway for this line were defined in the sweep function to generate the winglet. The mesh was generated with some refinements on the aircraft body. The number of elements and nodes utilized are listed as 4,675,041 and 883,286 , respectively.

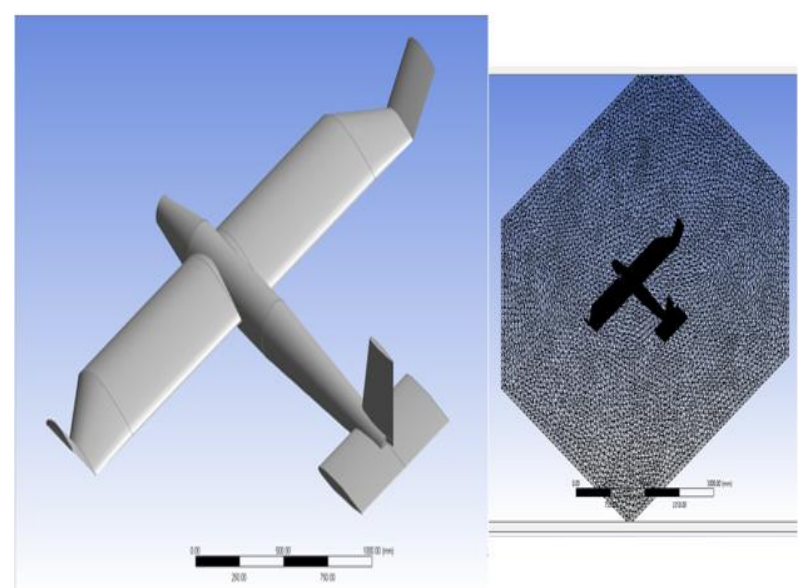

Figure 4 Full aircraft with $45^{\circ}$ winglets and mesh generated.

\subsection{CFD Modeling Technique}

Table 1 shows the ANSYS Fluent CFD turbulence modeling properties that are applied to the wing simulations. Majority of the flows are considered to fall under the turbulent category in the field of engineering. Therefore, it is necessary to consider the turbulence effects on the mean flow only rather resolving for all details related to turbulent fluctuations [10]. The turbulence model chosen for this study is SST K-Omega (SST k- $\omega$ ) in ANSYS Fluent, which provides accurate results for flow separation and turbulence simulation especially when analysing post-stall conditions. The standard equation for SST k- $\omega$ was given in [11], shown as the following:

$\frac{\partial k}{\partial t}+U_{j} \frac{\partial k}{\partial x_{j}}=P_{k}-\beta^{*} k \omega+\frac{\partial}{\partial x_{j}}\left[\left(v+\sigma_{k} v_{T}\right) \frac{\partial k}{\partial x_{j}}\right]$ (1) where $v_{T}$ is the kinematic eddy viscosity. The turbulence model was successfully used in the other vortex generator applications that further details can be found in [12-13].

The transport equations for the SST K-Omega (SST k- $\omega$ ) is provided as the following [14]:

$\frac{\partial}{\partial t}(\rho k)+\frac{\partial}{\partial x_{i}}\left(\rho k u_{i}\right)=\frac{\partial}{\partial x_{j}}\left[\left(\mu+\frac{\mu_{t}}{\sigma_{k}}\right) \frac{\partial k}{\partial x_{j}}\right]+\tilde{G}_{k}-$
$Y_{k}+S_{k}$ 
and

$$
\begin{aligned}
& \frac{\partial}{\partial t}(\rho \omega)+\frac{\partial}{\partial x_{i}}\left(\rho \omega u_{i}\right)=\frac{\partial}{\partial x_{j}}\left[\left(\mu+\frac{\mu_{t}}{\sigma_{\omega}}\right) \frac{\partial \omega}{\partial x_{j}}\right]+G_{\omega}- \\
& Y_{\omega}+D_{\omega}+S_{\omega}
\end{aligned}
$$

where,

$$
\begin{array}{c|l}
\widetilde{G}_{k} & \begin{array}{l}
\text { Generation of turbulence kinetic } \\
\text { energy due to mean velocity gradient }
\end{array} \\
G_{\omega} & \text { Generation of } \omega \\
Y_{k} \& Y_{\omega} & \text { Dissipation of k and } \omega \\
D_{\omega} & \text { Cross-diffusion term } \\
S_{k} \& S_{\omega} & \text { User defend source terms }
\end{array}
$$

\subsection{Grid Independence Study}

Model verification is done by varying the mesh intensity. The edge size of the mesh is varied and the results obtained are compared (Table 2). It can be noticed that Mesh 2 and 3 gave almost the same values and Mesh 1 is a little deviated from the results of mesh 2 and 3. This model verification is for simple case and has been repeated for all the cases. Depending on the geometry, face sizing is applied and hence the number of elements for each case varies. The model verification is not sufficient for verifying the results and hence we have conducted results verification using experimental means.

Table 2 Mesh intensity results.

\begin{tabular}{|l|l|l|l|}
\hline Mesh Type & Mesh 1 & Mesh 2 & Mesh 3 \\
\hline Elements & 73,036 & 207,822 & 630,214 \\
\hline Lift Force (N) & 4.578 & 4.932 & 5.038 \\
\hline Drag Force (N) & 1.123 & 1.085 & 0.962 \\
\hline $\begin{array}{l}\text { Improvement } \\
\text { in L/D (\%) }\end{array}$ & $0.0 \%$ & $11.5 \%$ & $28.4 \%$ \\
\hline
\end{tabular}

\subsection{Scaled-down Wing for Wind Tunnel Testing}

Three wing models (scaled down to half the original wing dimensions) were fabricated for wind tunnel testing as illustrated in Fig. 5. Their respective modifications were designed and manufactured while keeping ease of assembly/disassembly under consideration. The first wing was created as a simple case, the second wing was attached with rectangular

\begin{tabular}{|c|c|}
\hline Analysis Type & Computational Fluid Dynamics \\
\hline Problem Type & 3D Fluid Flow \\
\hline Model & Viscous SST k- $\omega$ \\
\hline Element Type & Tetrahedron \\
\hline DOF & $4\left(V_{\mathrm{x}} V_{\mathrm{y}} V_{\mathrm{z}}\right.$ and $\left.P\right)$ \\
\hline \multirow{4}{*}{$\begin{array}{l}\text { Boundary } \\
\text { Conditions }\end{array}$} & Steady State \\
\hline & Incompressible Flow \\
\hline & $\begin{array}{l}\text { Inlet Velocity } V_{\mathrm{x}}=12 \mathrm{~m} / \mathrm{s} ; V_{\mathrm{y}}= \\
V_{\mathrm{z}}=0\end{array}$ \\
\hline & Pressure Outlet \\
\hline Intensity & $\begin{array}{l}\text { Edge Size is different for wing } \\
\text { and airplane } \\
\text { Face Sizing is also applied }\end{array}$ \\
\hline
\end{tabular}
vortex generators, whereas the last wing was assembled with triangular vortex generators. Moreover, the winglets $\left(45^{\circ}, 90^{\circ}\right)$ were manufactured to mechanically fit all three wings. Needless to say, these wing designs were based on the same EPPLER 420 airfoil [15].

The winglets for the original wing were designed using the same airfoil EPPLER 420. They follow a decreasingly tapered shape starting with $220 \mathrm{~mm}$ leading to $70 \mathrm{~mm}$, as illustrated in Fig. 6. The winglet
Table 1 CFD modeling properties.

attachments were catered in the design phase to ensure an effective grip with the wing itself. Thereafter, rectangular and triangular vortex generators were designed and manufactured for the wing. After multiple simulative trials on CFD using all these modifications, triangular vortex generators and $45^{\circ}$ winglet exuded finer results; hence, being optimum choices, they were accommodated in the final assembly, as shown in Fig. 7. Figure 8 illustrates the CFD results for flow patterns over several vortex generators designs. These vortex generators are aligned in a row about $16 \%$ distance from the leading edge as suggested by [2-3].

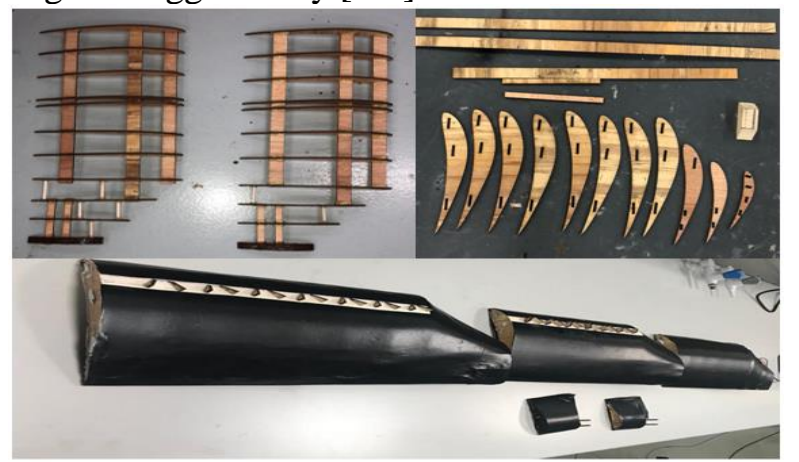

Figure 5 Wing models fabricated for Wind-Tunnel Testing. 


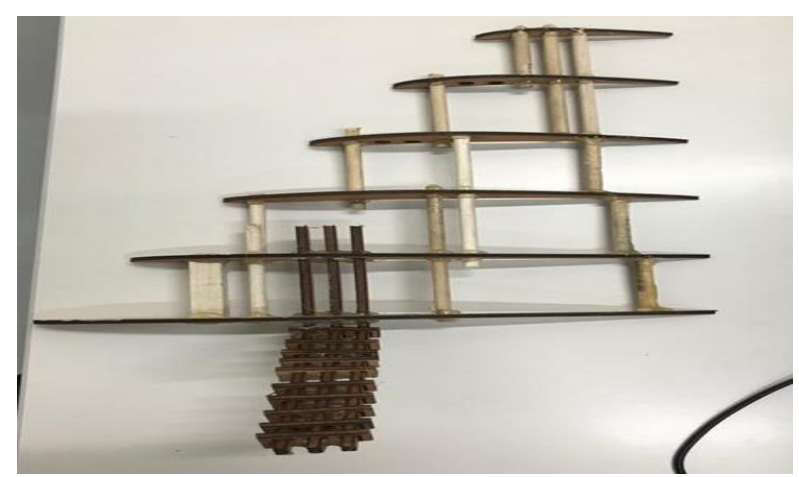

Figure 6 Winglet with attachment after assembly.

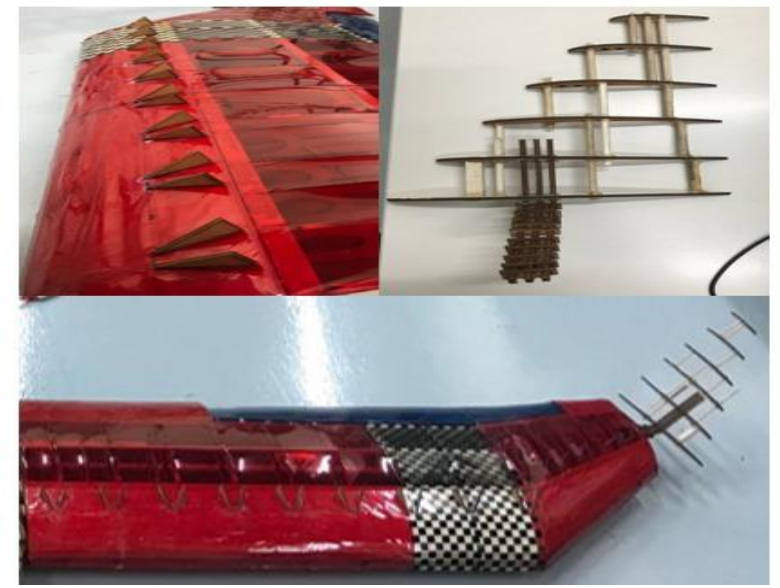

Figure 7 Final assembled wing with modifications.

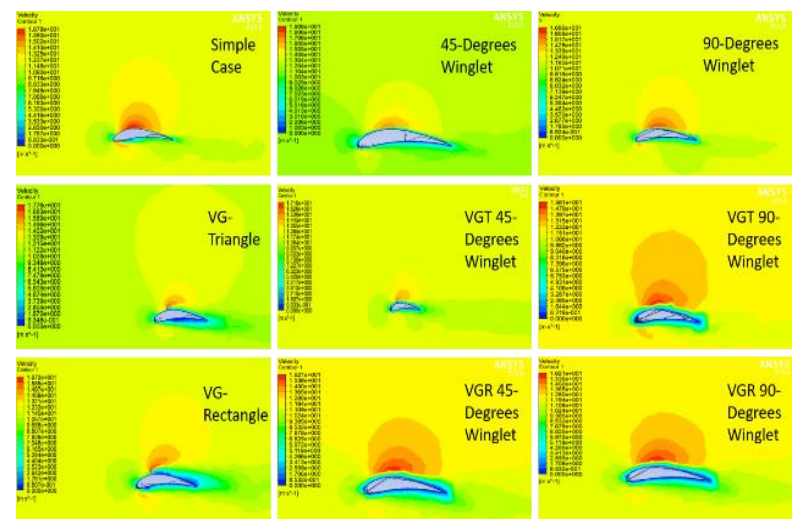

Figure 8 Velocity contours; VG-Vortex Generator; VGT-Vortex Generator Triangle; VGR-Vortex Generator Rectangle.

\subsection{Wind Tunnel Testing for CFD Validation}

Wind Tunnel Testing was carried out at UAE University in Al Ain. The lift and drag measurements were done using an open-typed subsonic wind tunnel, shown in Fig. 9 for the following wings configurations;

1. Simple Wing

2. Wing attached with rectangular VG's.

3. Wing attached with triangular VG's.

4. Two $45^{\circ}$ and $90^{\circ}$ detachable winglets.

The blockage ratio of $5.0 \%-5.3 \%$ is generally accepted as sufficiently low to avoid significant low wall interference effect [16-18]. Figure 10 shows for example measurements for wing with rectangular vortex generators with winglet at angle of attack equal to $\alpha=0^{\circ}$. Table 3 illustrates the comparison. It can be noticed that the percentage error is in the acceptable range for velocities $8.011 \mathrm{~m} / \mathrm{s}$ and $12.0165 \mathrm{~m} / \mathrm{s}$. For velocities $16.022 \mathrm{~m} / \mathrm{s}$ and 20.0275 $\mathrm{m} / \mathrm{s}$, a lot of vibration was observed while performing the wind tunnel test which could be the reason for the large deviation in values. Since the model is operating in the velocity range of $12 \mathrm{~m} / \mathrm{s}$, the percentage error between the wind tunnel test and the CFD results is acceptable and hence the results are verified.

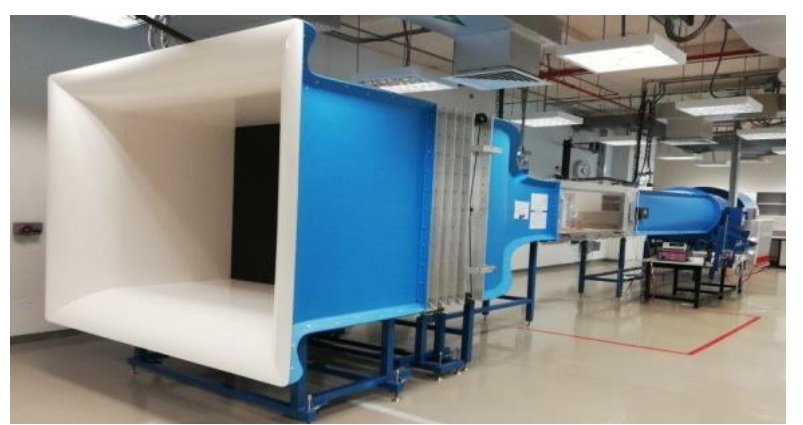

Figure 9 Open-typed subsonic wind tunnel.

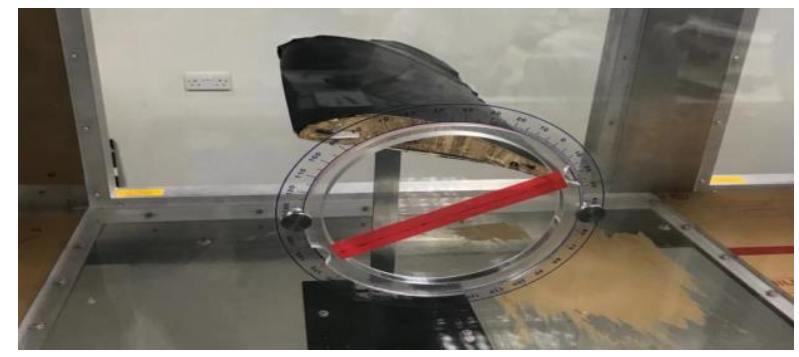

Figure 10 Simple wing at angle of attack equal to $\alpha$ $=12^{\circ}$.

Table 3 Wind tunnel (WT) and CFD data

\begin{tabular}{|l|l|l|l|l|}
\hline Speeds (m/s) & 8 & 12 & 16 & 20 \\
\hline Lift, (N) (WT) & 2.74 & 8.04 & 19.13 & 37.57 \\
\hline Drag, (N) (WT) & 0.54 & 1.40 & 2.74 & 4.81 \\
\hline Lift, (N) (CFD) & 3.30 & 7.38 & 13.38 & 20.98 \\
\hline Drag, (N) (CFD) & 0.47 & 1.02 & 1.81 & 2.81 \\
\hline Error Lift \% & 20.1 & 8.3 & 30.0 & 44.2 \\
\hline Error Drag \% & 13.3 & 27.3 & 33.9 & 41.6 \\
\hline
\end{tabular}

\section{Results and Discussion}

Computational Fluid Dynamic analysis is executed on the following cases, as shown in Table 4. Each case is individually analyzed at four angle of attacks 
$\left(0^{\circ}, 7.5^{\circ}, 13^{\circ}\right.$ and $\left.15^{\circ}\right)$ and all respective results are illustrated in this paper. Each row represents a set of three trials compared together as one case; hence, there are 9 cases.

Table 4 Nine Trials for CFD analysis.

\begin{tabular}{|l|l|l|l|}
\hline $\begin{array}{l}\text { Case } \\
1\end{array}$ & $\begin{array}{l}\text { Simple } \\
\text { Wing }\end{array}$ & $\begin{array}{l}\text { Simple with } \\
45^{\circ} \text { Winglet }\end{array}$ & $\begin{array}{l}\text { Simple with } \\
90^{\circ} \text { Winglet }\end{array}$ \\
\hline $\begin{array}{l}\text { Case } \\
2\end{array}$ & $\begin{array}{l}\text { Simple } \\
\text { with RVG }\end{array}$ & $\begin{array}{l}45^{\circ} \text { Winglet } \\
\text { with RVG }\end{array}$ & $\begin{array}{l}90^{\circ} \text { Winglet } \\
\text { with RVG }\end{array}$ \\
\hline $\begin{array}{l}\text { Case } \\
3\end{array}$ & $\begin{array}{l}\text { Simple } \\
\text { with TVG }\end{array}$ & $\begin{array}{l}45^{\circ} \text { Winglet } \\
\text { with TVG }\end{array}$ & $\begin{array}{l}90^{\circ} \text { Winglet } \\
\text { with TVG }\end{array}$ \\
\hline
\end{tabular}

\subsection{Case 1}

Figure 11 illustrates the velocity contours for the first three trials. The midpoint plane contours of each wing distinctly demonstrate peak velocity at the top surface of the airfoil and is observed to increase as the AOA is increased. Whereas, the velocity is observed to decrease below the airfoil. Moreover, $45^{\circ}$ winglet displays higher velocities at the top of its cross-section when compared to $90^{\circ}$ winglet.

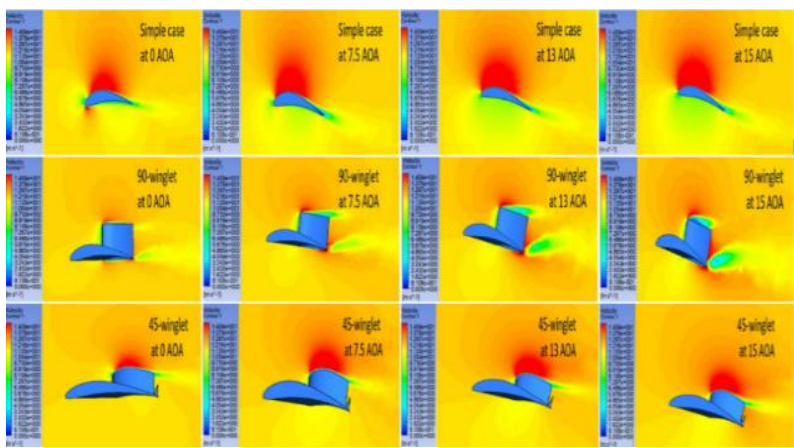

Figure 11 Velocity contours for Case 1.

Figure 12 illustrates the pressure distribution contours for every trial. The contours indicate a higher pressure distribution below the wing for every trials. Table 5 shows the results of lift force and drag force for Case 1. Based on contours and CFD results, lift demonstrates a correlation with the increase in AOA for every trial [19]. Moreover, using winglets have apparently displayed an increase in overall lift of the wing when compared to the simple wing trial. However, there was a slight increase in drag at lower AOAs using winglets, but it improved as AOA was further raised beyond $7.5^{\circ}$. Furthermore, $45^{\circ}$ winglet proved to demonstrate better lift and less drag at higher AOAs compared to simple and $90^{\circ}$ winglet statistics; hence, proving to be the best option.

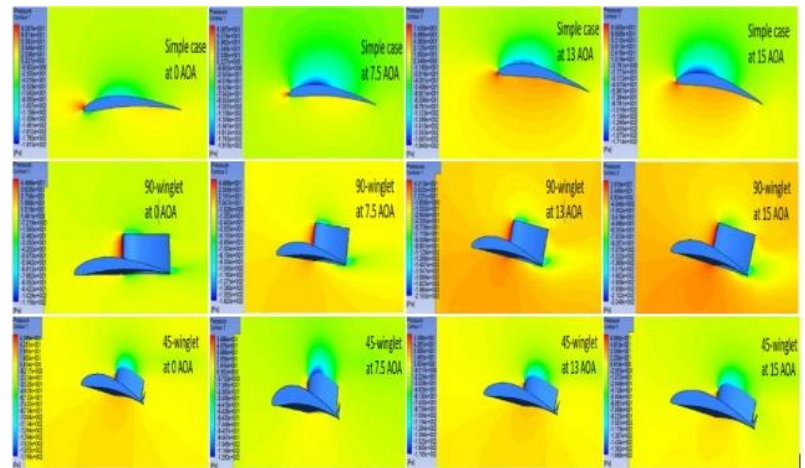

Figure 12 Pressure distribution contours for Case 1.

Table 5 CFD results for Case 1.

\begin{tabular}{|l|l|l|l|}
\hline No. & Case & $\begin{array}{l}\text { Lift } \\
(\mathrm{N})\end{array}$ & $\begin{array}{l}\text { Drag } \\
(\mathrm{N})\end{array}$ \\
\hline 1 & Simple with $0^{\circ} \mathrm{AOA}$ & 23.4 & 2.21 \\
\hline 2 & Simple with $7.5^{\circ} \mathrm{AOA}$ & 40.5 & 5.20 \\
\hline 3 & Simple with $13^{\circ} \mathrm{AOA}$ & 57.1 & 9.30 \\
\hline 4 & Simple with $15^{\circ} \mathrm{AOA}$ & 59.8 & 10.10 \\
\hline \multicolumn{3}{|l|}{} \\
\hline 1 & $\begin{array}{l}\text { Simple with } 0^{\circ} \mathrm{AOA} \& 90^{\circ} \\
\text { winglet }\end{array}$ & 20.58 & 2.35 \\
\hline 2 & $\begin{array}{l}\text { Simple with } 7.5^{\circ} \mathrm{AOA} \& 90^{\circ} \\
\text { winglet }\end{array}$ & 43.4 & 6.03 \\
\hline 3 & $\begin{array}{l}\text { Simple with } 13^{\circ} \mathrm{AOA} \& 90^{\circ} \\
\text { winglet }\end{array}$ & 51.2 & 8.40 \\
\hline 4 & $\begin{array}{l}\text { Simple with } 15^{\circ} \mathrm{AOA} \& 90^{\circ} \\
\text { winglet }\end{array}$ & 61.5 & 11.10 \\
\hline 1 & $\begin{array}{l}\text { Simple with } 0^{\circ} \mathrm{AOA} \& 45^{\circ} \\
\text { winglet }\end{array}$ & 26.86 & 2.71 \\
\hline 2 & $\begin{array}{l}\text { Simple with } 7.5^{\circ} \mathrm{AOA} \& 45^{\circ} \\
\text { winglet }\end{array}$ & 48.56 & 5.42 \\
\hline 3 & $\begin{array}{l}\text { Simple with } 13^{\circ} \mathrm{AOA} \& 45^{\circ} \\
\text { winglet }\end{array}$ & 62.62 & 8.78 \\
\hline 4 & $\begin{array}{l}\text { Simple with } 15^{\circ} \mathrm{AOA} \& 45^{\circ} \\
\text { winglet }\end{array}$ & 63.57 & 9.91 \\
\hline
\end{tabular}

\subsection{Case 2}

Figure 13 illustrates the velocity contours for the three trials conducted previously but now using Rectangular Vortex Generators (RVG). All contours demonstrate increased velocities at the top, but also revealing regions of flow separation, which tends to increase with the increase in AOA [20].

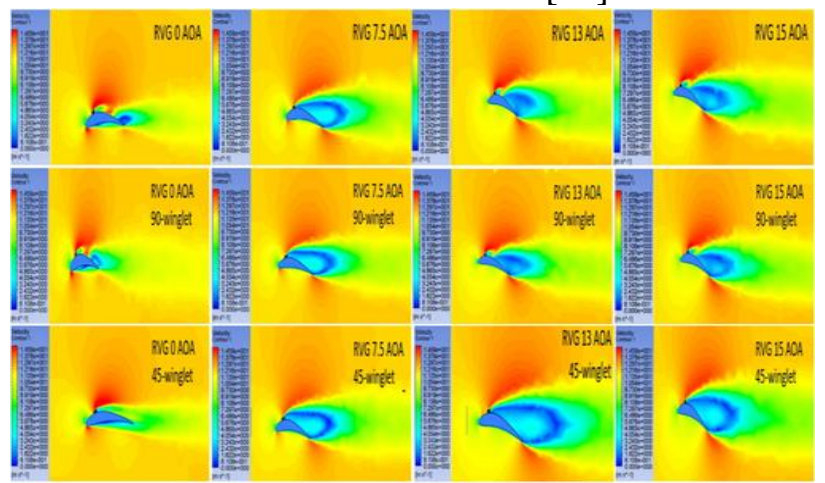


Figure 13 Velocity contours for Case 2.

Figure 14 represents the pressure contours displaying an increased pressure at the top crosssection of airfoil for all runs. The pressure is observed to decrease on the top of airfoil as the AOA is increased. In fact, the pressure is observed to reach the lowest (top surface) at higher AOAs using RVG with $45^{\circ}$ winglet. Table 6 shows the results of lift force and drag force for Case 2. Considering all CFD results and contours, the drag forces for all runs demonstrate similar pattern without any major fluctuations. However, there are crucial changes in lift forces that segregates each trial from another. Comparing simple with $90^{\circ}$ winglet, it is observed that the lift force has decreased with drags showing almost negligible changes. Hence, using $90^{\circ}$ winglet with RVGs is not the best choice and is ruled out. Furthermore, comparing simple with $45^{\circ}$ winglet displays improved changes in lift and having drags almost similar. There is approximately $15-20 \%$ increase in overall lift using RVGs with $45^{\circ}$ winglet; thus, making it the best choice.

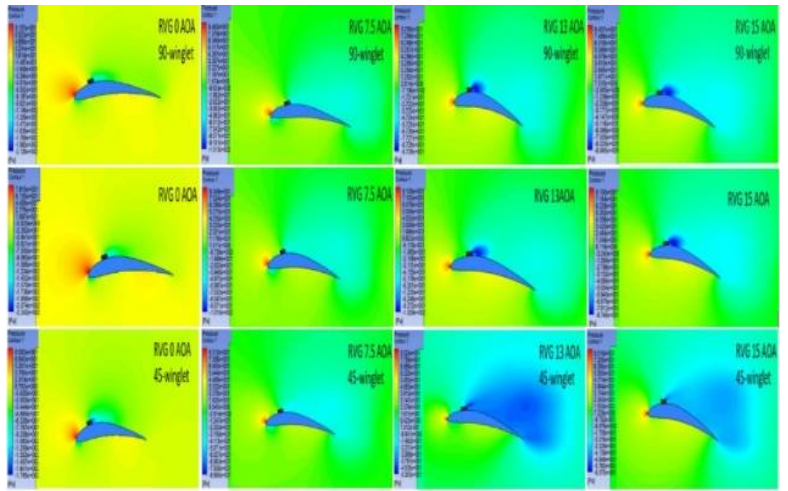

Figure 14 Pressure distribution contours for Case 2.

Table 6 CFD results for Case 2.

\begin{tabular}{|l|l|l|l|}
\hline No. & Case 2 & $\begin{array}{l}\text { Lift } \\
(\mathrm{N})\end{array}$ & $\begin{array}{l}\text { Drag } \\
(\mathrm{N})\end{array}$ \\
\hline 1 & Rec. VG with $0^{\circ} \mathrm{AOA}$ & 14.91 & 5.04 \\
\hline 2 & Rec. VG with $7.5^{\circ} \mathrm{AOA}$ & 20.68 & 8.1 \\
\hline 3 & Rec. VG with $13^{\circ} \mathrm{AOA}$ & 31.57 & 11.65 \\
\hline 4 & Rec VG with $15^{\circ} \mathrm{AOA}$ & 33.03 & 12.75 \\
\hline \multicolumn{3}{|l|}{} \\
\hline 1 & $\begin{array}{l}\text { Rec. VG with } 0^{\circ} \mathrm{AOA} \& \text { } 90^{\circ} \\
\text { winglet }\end{array}$ & 14.2 & 5.76 \\
\hline 2 & $\begin{array}{l}\text { Rec. VG with } 7.5^{\circ} \mathrm{AOA} \& 90^{\circ} \\
\text { winglet }\end{array}$ & 19.65 & 8.36 \\
\hline 3 & $\begin{array}{l}\text { Rec. VG with } 13^{\circ} \mathrm{AOA} \& 90^{\circ} \\
\text { winglet }\end{array}$ & 30.46 & 11.52 \\
\hline 4 & $\begin{array}{l}\text { Rec. VG with } 15^{\circ} \mathrm{AOA} \& 90^{\circ} \\
\text { winglet }\end{array}$ & 31.34 & 12.6 \\
\hline & \multicolumn{3}{|l}{} \\
\hline
\end{tabular}

\begin{tabular}{|l|l|l|l|}
\hline 1 & $\begin{array}{l}\text { Rec. VG with } 0^{\circ} \text { AOA with } \\
45^{\circ} \text { winglet }\end{array}$ & 18.82 & 5.02 \\
\hline 2 & $\begin{array}{l}\text { Rec. VG with 7.5 AOA with } \\
45^{\circ} \text { winglet }\end{array}$ & 27.76 & 8.42 \\
\hline 3 & $\begin{array}{l}\text { Rec. VG with 13 AOA with } \\
45^{\circ} \text { winglet }\end{array}$ & 35.06 & 11.52 \\
\hline 4 & $\begin{array}{l}\text { Rec. VG with 15 AOA with } \\
45^{\circ} \text { winglet }\end{array}$ & 38.57 & 12.8 \\
\hline
\end{tabular}

\subsection{Case 3}

Figure 15 illustrates the velocity contours for the three trials having modified with Triangular Vortex Generators (TVG).

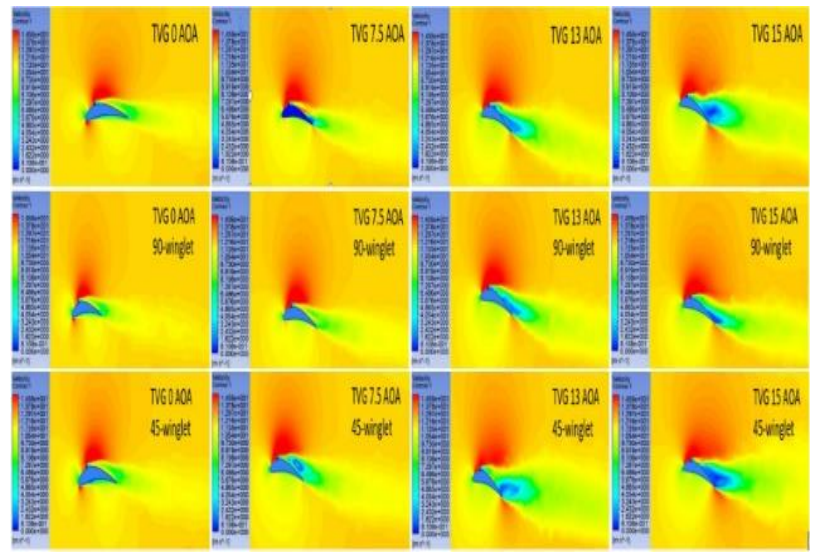

Figure 15 Velocity contours for Case 3.

Figure 16 illustrates the pressure distribution contours for all trials using TVGs. The contours display an increased pressure distribution at the top cross-section of airfoil as the AOA is increased. Table 7 shows the results of lift force and drag force for Case 3. Comparing simple TVG and $90^{\circ}$ winglet TVG. There is a noticeable decrease in drag at lower AOAs and having similar drags at higher AOAs, but there is a significant increase in lift force for $90^{\circ}$ winglet. Thus, it eliminates simple case with TVG from the list. Further comparing TVG $90^{\circ}$ winglet and TVG $45^{\circ}$ winglet, the lift is higher at lower AOA for $45^{\circ}$ winglet and is observed to be similar at higher AOAs for both cases. Moreover, the drags represent similar fluctuations at each AOA. Hence, TVG with $45^{\circ}$ winglet is the best choice among these trials.

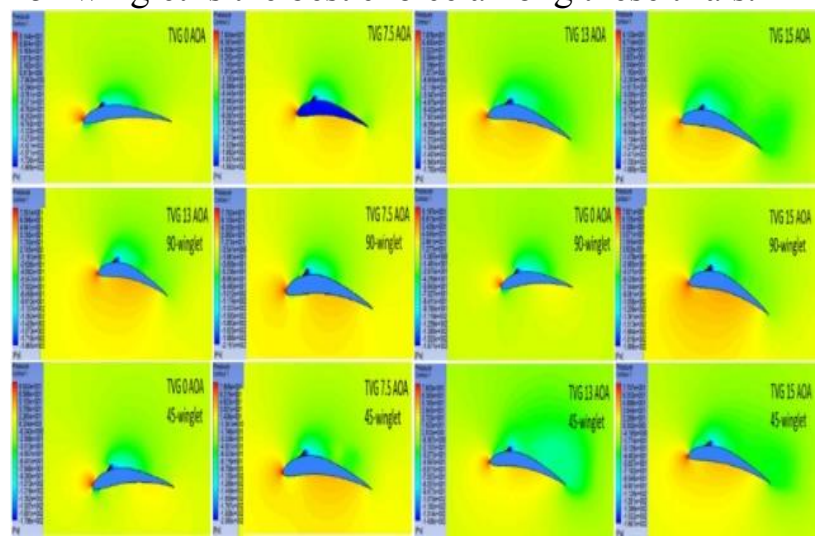


Figure 16 Pressure distribution contours for Case 3.

Table 7 CFD results for Case 3.

\begin{tabular}{|c|c|c|c|}
\hline No. & Case 3 & $\begin{array}{l}\text { Lift } \\
(\mathrm{N})\end{array}$ & $\begin{array}{l}\text { Drag } \\
(\mathrm{N})\end{array}$ \\
\hline 1 & Tri. VG with $0^{\circ} \mathrm{AOA}$ & 14.91 & 5.04 \\
\hline 2 & Tri. VG with $7.5^{\circ} \mathrm{AOA}$ & 37.89 & 8.07 \\
\hline 3 & Tri. VG with $13^{\circ} \mathrm{AOA}$ & 41.01 & 10.29 \\
\hline 4 & Tri. VG with $15^{\circ} \mathrm{AOA}$ & 41.8 & 10.66 \\
\hline 1 & $\begin{array}{l}\text { Tri. VG with } 0^{\circ} \text { AOA \& } 90^{\circ} \\
\text { winglet }\end{array}$ & 22.32 & 4.21 \\
\hline 2 & $\begin{array}{l}\text { Tri. VG with } 7.5^{\circ} \text { AOA \& } \\
90^{\circ} \text { winglet }\end{array}$ & 34.53 & 6.96 \\
\hline 3 & $\begin{array}{l}\text { Tri. VG with } 13^{\circ} \text { AOA \& } \\
90^{\circ} \text { winglet }\end{array}$ & 43.72 & 10.77 \\
\hline 4 & $\begin{array}{l}\text { Tri. VG with } 15^{\circ} \text { AOA \& } \\
90^{\circ} \text { winglet }\end{array}$ & 44.06 & 11.52 \\
\hline 1 & $\begin{array}{l}\text { Tri. VG with } 0^{\circ} \mathrm{AOA} \text { with } \\
45^{\circ} \text { winglet }\end{array}$ & 25.89 & 3.88 \\
\hline 2 & $\begin{array}{l}\text { Tri. VG with } 7.5^{\circ} \text { AOA } \\
\text { with } 45^{\circ} \text { winglet }\end{array}$ & 44.49 & 7.25 \\
\hline 3 & $\begin{array}{l}\text { Tri. VG with } 13^{\circ} \text { AOA with } \\
45^{\circ} \text { winglet }\end{array}$ & 44.31 & 11.01 \\
\hline 4 & $\begin{array}{l}\text { Tri. VG with } 15^{\circ} \text { AOA with } \\
45^{\circ} \text { winglet }\end{array}$ & 44.36 & 10.87 \\
\hline
\end{tabular}

\subsection{Airplane Model}

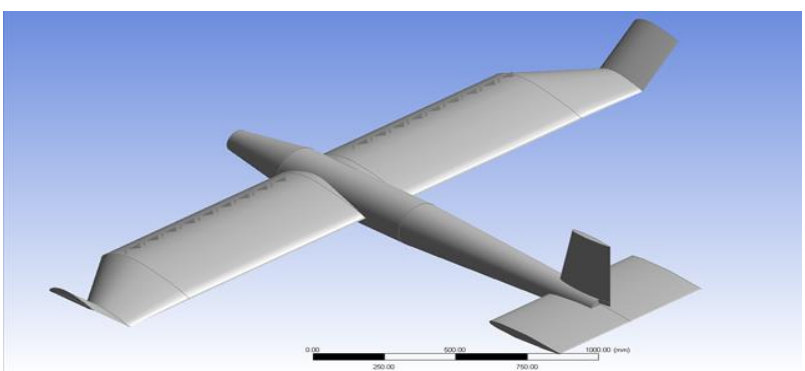

Figure 17 Geometric body of the airplane-VGT 45degrees winglet model.

The geometry in Fig. 4 is further enhanced with the use of triangular vortex generators, as shown in Fig. 17. The CFD results that have obtained shows that adding the vortex generator will lead to $40 \%$ reduction in the lift force compared to the airplane$45^{\circ}$ winglet model (with no VGs), as shown in Fig. 18. Figure 19 shows the whole manufactured RC plane with the attached winglets and landing gear.

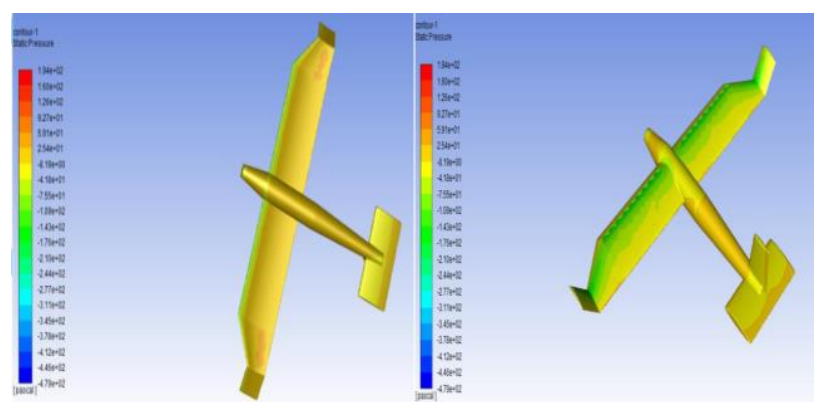

Figure 18 Pressure distribution over the bottom and top surfaces of the airplane-VGT 45-degrees winglet model.

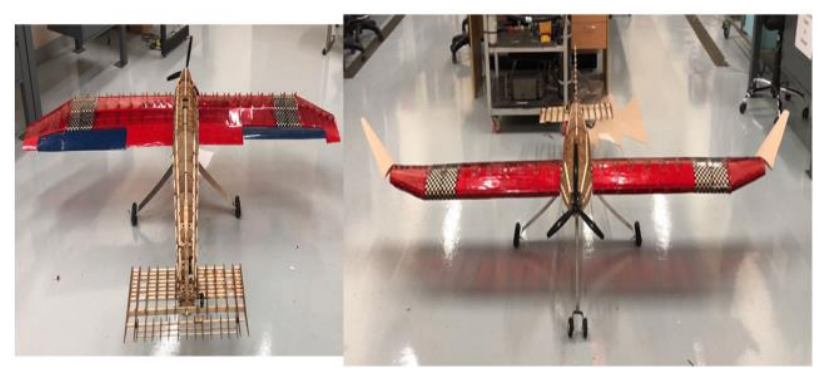

Figure 19 Whole RC plane with the winglet.

\section{Conclusions}

In conclusion, aerodynamic optimization of airplanes wing by utilizing winglets and vortex generators is performed. Finite Element Simulation is initially performed using ANSYS Fluent for different wing designs. The simulation was conducted at various speeds $(8 \mathrm{~m} / \mathrm{s}, 12 \mathrm{~m} / \mathrm{s}, 16 \mathrm{~m} / \mathrm{s}, 20 \mathrm{~m} / \mathrm{s})$ and angle of attacks $\left(0^{\circ}, 7.5^{\circ}, 13^{\circ}, 15^{\circ}\right)$ for all the designs. The results obtained from the simulation model are validated by wind tunnel experiment. The CFD results show that the best model in aerodynamics analysis is the airplane with $45^{\circ}$ winglet model, which has higher lift force and lower drag force when compared to other cases. These findings are also consistent with the modification analysis by the wind tunnel testing that has been done on different set of wing models and it shows that the winglet case is the best for the wing. Finally, the design and manufacturing were carried out based on these findings and all the constraints provided by SAE competition were kept under consideration. In coming times, the effect of the position of the vortex generator on the wings may be explored. 


\section{References}

[1]n.d. SAE AERO DESIGN. Accessed June 24, 2020. https://www.saeaerodesign.com.

[2] El Ghazali, A. F., and S. S. Dol. 2020. "Aerodynamic Optimization of Unmanned Aerial Vehicle through Propeller Improvements." Journal of Applied Fluid Mechanics, vol. 13, no. 3, 793-803.

[3] Yeong, Siew Ping, and Sharul Sham Dol. 2016. "Aerodynamic Optimization of Micro Aerial Vehicle." Journal of Applied Fluid Mechanics, vol. 9, no. 5, 21112121.

[4] Dol., Sharul Sham. 2020. "Aerodynamic optimization of unmanned aerial vehicle for offshore search and rescue (SAR) operation." IOP Conference Series: Materials Science and Engineering, vol. 715, no. 1, p. 012015. IOP Publishing.

[5] Abdullah, A. Q., and S. S. Dol. 2020. "Aerodynamic Investigation and Design of Dimpled-Surface Airfoil for UAV Propellers." 2020 Advances in Science and Engineering Technology International Conferences (ASET). Dubai, United Arab Emirates: IEEE. 1-5.

[6] Dol, Sharul S. 2013. "Weakened Vortex Shedding from a Rotating Cylinder." International Journal of Mechanical and Mechatronics Engineering, vol. 7, no. 10, 2013-2020.

[7] Azeez, Abid Abdul, Mohamed Gadala, Nasr Al Khudhiri, and Sharul Sham Dol. 2019. "Aerodynamics Optimization of RC Plane Winglet." 2019 8th International Conference on Modeling Simulation and Applied Optimization (ICMSAO). IEEE. 1-5.

[8] Kumar, G. 2016. "Comparative Analysis of Varies Vortex Generator for a NACA." International Journal of Innovative Studies in Science and Engineering Technology, 03-06.

[9] Dol, Sh. Sham, S. Shahid Pervaiz, M. Uzair, Sh. Khalid Bashir, and M. Mustafa Elzughbi. 2020. "Design of Solarpowered Endurance Glider with Vortex Generators." Journal of Renewable Energy Research and Application (RERA).

[10] DOL, Sharul Sham; CHAN, Hiang Bin; WEE, Siaw Khur. FSI SIMULATION OF A FLEXIBLE VORTEX GENERATOR AND THE EFFECTS OF VORTICES TO THE HEAT TRANSFER PROCESS. Platform : A Journal of Engineering, [S.1.], v. 4, n. 2, p. 58-69, June 2020.

[11] ABDULlAH, Abdul Qader, Abid Abdul Azeez, Sharul Sham Dol, Mohammad Khan, and Mior Azman
Meor Said. 2020. "SIMULATION STUDY ON VORTEX-INDUCED VIBRATION AIR WAKE ENERGY FOR AIRPORT RUNAWAY APPLICATION: A PRELIMINARY ANALYSIS." Platform : A Journal of Engineering, [S.1.], v. 4, n. 3, 38-47.

[12] Dol, Sharul Sham, Siaw Khur Wee, Hiang Bin Chan, Perumal Kumar. 2019. "Turbulence Characteristics behind a Flexible Vortex Generator" WSEAS TRANSACTIONS ON FLUID MECHANICS, 14, 1-7.

[13] Dol, Sharul Sham, Hiang Bin Chan, Siaw Khur Wee, Kumar Perumal. 2020. "The effects of flexible vortex generator on the wake structures for improving turbulence." IOP Conference Series: Materials Science and Engineering, vol. 715, no. 1, p. 012070. IOP Publishing.

[14]2013. ANSYS Fluent Theory Guide. Canonsburg: ANSYS.

[15] n.d. EPPLER 420 AIRFOIL. Accessed June 24, 2020. http://airfoiltools.com/airfoil/details?airfoil=e420-il.

[16] Yong, TH, SS Dol. 2015. "Design and Development of Low-Cost Wind Tunnel for Educational Purpose". IOP Conference Series: Materials Science and Engineering, 78, 012039.

[17] Dol, Sharul Sham, Mohd Arief Mohd Nor and Muhamad Khairun Kamaruzaman. 2006. "Flow visualization of the vortex shedding of a stationary circular cylinder by an improved smoke-wire technique". WSEAS Transactions on Fluid Mechanics, Issue 6, Volume 1. 745752.

[18] Dol, Sharul Sham, Mohd Arief Mohd Nor and Muhamad Khairun Kamaruzaman. 2006. "An improved smoke-wire flow visualization technique". Proceedings of the 4th WSEAS International Conference on Fluid Mechanics and Aerodynamics, Elounda. Greece. August 21-23. 231-236.

[19] Iqbal, Muhammad Ahsan, Abdul Qader Abdullah, Sharul Sham Dol. 2020. "Design of self-powered surveillance RC aircraft." International Journal of Engineering Research in Mechanical and Civil Engineering (IJERMCE) Volume 5.

[20] Eid, Saif Eldin, and Sharul Sham Dol. 2019. "Design and Development of Lightweight-High Endurance Unmanned Aerial Vehicle for Offshore Search and Rescue Operation." In 2019 Advances in Science and Engineering Technology International Conferences (ASET). IEEE. 15.

\section{Creative Commons Attribution License 4.0 (Attribution 4.0 International, CC BY 4.0)}

This article is published under the terms of the Creative Commons Attribution License 4.0

https://creativecommons.org/licenses/by/4.0/deed.en_US 